\title{
Higher Behavioral Profile of Mindfulness and Psychological Flexibility is Related to Reduced Impulsivity in Smokers, and Reduced Risk Aversion Regardless of Smoking Status
}

\begin{abstract}
Empirical evidence suggests that mindfulness, psychological flexibility, and addiction are interrelated in decision making. In our study, we investigated the relationship of the behavioral profile, composed of mindfulness and psychological flexibility, and smoking status on delay and probability discounting. We demonstrated the interaction of the behavioral profile of mindfulness and psychological flexibility (lower or higher) and smoking status on delay discounting. We found that individuals who smoked and displayed higher mindfulness and psychological flexibility devalued rewards at a slower rate, compared to smokers with a lower profile. Importantly, in those with a higher profile, smokers discounted rewards no differently than nonsmokers. Smokers with a lower profile did display, however, increased impulsivity, compared to nonsmokers. These results suggest that behavioral interventions aiming to modify the behavioral profile with regard to mindfulness and psychological flexibility can indeed support the regulation of elevated impulsivity in smokers to equate with that of nonsmokers. In probability discounting, we observed that individuals with a higher profile displayed lower discounting rates, i.e., were less risk-averse, with no other significant main effect or interaction.
\end{abstract}

Keywords: smoking, mindfulness, psychological flexibility, delay discounting, probability discounting

Supported by an increasing amount of evidence, modern behavioral economics offers an explanation for the onset, maintenance, and treatment of addiction as pathological reward processing (Bickel, Koffarnus, Moody, \& Wilson, 2014). In parallel, contextual behavioral science proposes interventions based on mindfulness and psychological flexibility that aim to modify maladaptive behaviors (Hayes, Levin, Plumb-Vilardaga, Villatte, \& Pistorello, 2013). In the present work, we bring together the traditions of behavioral economics and contextual behavioral science and link them to research on smoking.

Smoking remains one of the most common addictions and one of the leading preventable causes of death globally (Finucane et al., 2011). Smoking and exposure to secondhand smoke are responsible for approximately 6.3 million deaths worldwide (Lim et al., 2012), and is of particular importance in Eastern Europe, where the prevalence of the smoking habit is high (Ezzati \& Riboli, 2013). A number of studies have emphasized that mortality in middle-aged smokers is is two to three times greater than mortality in nonsmokers, and that the lifespan of smokers is reduced by an average of approximately 10 years. Individuals who begin smoking at a young age but stop smoking at the age of 30, 40, or 50 years gained approximately 10, 9, and 6 years of life expectancy, respectively, compared to those who continue smoking (Doll, Peto, Boreham, \& Sutherland, 2004; Jha et al., 2013; Jha \& Peto, 2014; Pirie, Peto, Reeves, Green, \& Beral, 2013; Thun et al., 2013).

There is ample evidence from behavioral economics linking smoking to measures of delay and probability

\footnotetext{
* SWPS University of Social Sciences and Humanities, Chodakowska 19/31, 03-815 Warsaw, Poland
} 
discounting. Delay discounting refers to a decrease in the subjective value of a reward as the delay to its delivery increases (Mazur, 1987). Correspondingly, probability discounting is observed when the subjective value of a reward decreases due to the decreasing probability of obtaining it (e.g., Rachlin, Raineri, \& Cross, 1991). The more a reward is devalued by an increase in delay or a decrease in the probability of obtaining that reward, the higher is the rate of delay or probability discounting, respectively. These measures can vary from individual to individual. For example, a higher delay discounting rate corresponds to a tendency to choose smaller, but sooner rewards over rewards that are larger, but more delayed. In intertemporal choice, such an observation is considered to be a proxy of greater impulsivity (Logue, 1988). Correspondingly, a higher probability discounting rate corresponds to a tendency to choose more certain rewards over those that are less certain to be obtained (Shead \& Hodgins, 2009), and is associated with greater risk aversion. In psychology, impulsivity can be defined with relevance to several phenomena. Following the approach established in discounting research, we refer to impulsivity as manifested by steeper delay discounting (Madden \& Johnson, 2010). Although impulsivity can also be considered in terms of risk seeking and risk aversion, as indexed by the probability discounting rate (Green \& Myerson, 2013), we refer to delay discounting as reflecting impulsivity and to probability discounting as reflecting risk aversion.

Previous studies have established a robust relevance of discounting measures in addiction research (Amlung, Vedelago, Acker, Balodis, \& MacKillop, 2017; Barlow, McKee, Reeves, Galea, \& Stuckler, 2016). In a metaanalysis by MacKillop and colleagues (2011) it was found that individuals with an addiction discounted delayed rewards more steeply. Importantly, discounting has been shown to be a powerful paradigm that can provide a conceptual platform to account for the onset and maintenance of addiction (Mitchell, 2004). This is prominently evidenced in smoking addiction. An increasing body of evidence points to increased discounting in smokers (for a review, see Barlow et al., 2016). Moreover, increased delay discounting predicts poorer outcomes of addiction treatment, particularly for smoking addiction (Krishnan-Sarin et al., 2007; MacKillop \& Kahler, 2009) and increases the risk of a relapse after smoking cessation (López-Torrecillas et al., 2014; Sheffer et al., 2014; Yoon et al., 2007).

Some researchers even argue delay discounting to be a neurobehavioral marker of addiction (Bickel et al., 2014) and that discounting measures can provide an index for discerning between smokers and nonsmokers. Importantly, while there is substantial work that links delay discounting and smoking, evidence of the relationship between smoking and probability discounting remains inconclusive. In particular, Mitchell (1999) found that the discounting of delayed, but not probabilistic rewards, is higher in smokers compared to nonsmokers. This is consistent with research by Ohmura, Takahashi, and Kitamura (2005), who also reported differences in delay, but not probability discounting, related to the degree of smoking in light to moderate smokers. On the other hand, some evidence links addictions with probability discounting (Reynolds, Karraker, Horn, \& Richards, 2003; Reynolds, Richards, Horn, \& Karraker, 2004), for example, altered probability discounting was found in smokers following acute nicotine abstinence (Mitchell, 2004; Yi \& Landes, 2012).

Despite the behavioral, neurobiological, and genetic evidence suggesting the individual discounting rate to be relatively stable over time (MacKillop et al., 2012; Odum, 2011), several research reports provide substantial evidence that interventions may effectively alter the rate at which rewards are discounted (Gray \& MacKillop, 2015). These include cognitive and behavioral strategies such as working memory training (Bickel, Yi, Landes, Hill, \& Baxter, 2011), contracts in therapy to avoid preference reversals (Peysakhovich, 2014), choice bundling or bracketing (Ainslie \& Monterosso, 2003; Read, Loewenstein, \& Rabin, 1999), and motivational interventions aimed to identify and highlight the value of delayed outcomes (Murphy et al., 2012). One area of intervention that recently continues to gain an increased attention of researchers concerns interventions related to mindfulness and psychological flexibility as defined by contextual behavioral science a research paradigm, rooted in radical behaviorism, that underlies the development of acceptance and commitment therapy (for a comprehensive description, see Hayes, Barnes-Holmes, \& Wilson, 2012).

\section{Mindfulness and psychological flexibility}

Mindfulness, as defined by Bishop and colleagues (2004), includes two components: (1) attention that allows a person to notice mental events as they occur in the present moment (mindful awareness); and (2) a particular stance toward those events that is characterized by openness, curiosity, and acceptance (mindful acceptance). The first component is related to abilities such as sustaining attention, flexibly switching it from one event to another, as well as the inhibition of elaborative processing, i.e., noticing instead of analyzing. The second component is related to taking a de-centered, nonjudgmental perspective of one's thoughts and feelings. In this perspective, mindfulness can be treated as a mode of awareness that can be developed, trained, and employed as a clinical approach to responding to individual emotional distress. It has been proven effective in addressing problems related to an intolerance of negative affect and subsequent behavioral avoidance, enabling the individual to adopt more adaptive strategies (Marlatt, 2002; Roemer, Williston, \& Rollins, 2015; Teasdale, Segal, \& Williams, 1995). Research regarding the effectiveness of mindfulness-based interventions is emerging rapidly (for a review, see Cullen, 2011), and involve different settings, such as schools (Zenner, Herrnleben-Kurz, \& Walach, 2014) and primary care (Demarzo et al., 2015), as well as various methods of delivery, such as online interventions (Spijkerman, Pots, \& Bohlmeijer, 2016) or mobile applications (Plaza, Demarzo, 
Herrera-Mercadal, \& García-Campayo, 2013). It has been demonstrated that mindfulness-based interventions can be an effective approach for treating smoking addiction. Individuals treated with these interventions were more likely to stop smoking than those who had standard treatment (Brewer et al., 2011). In addition, following a brief mindfulness-based intervention focused on noticing, but not acting on the urge to smoke, it was reported that individuals smoked less ("urge surfing", Bowen \& Marlatt, 2009), or reduced daily cigarette use after introducing daily mindfulness meditation practice (Ruscio, Muench, Brede, \& Waters, 2016). These studies, even without a determination of mechanisms underlying the intervention effectiveness, show promising results (for a review, see de Souza et al., 2015). However, there is still a need for further research to investigate the mechanisms by which these interventions can bring about behavioral change.

Mindfulness is closely related to the concept of the psychological flexibility model, proposed by Hayes and colleagues (Hayes, Luoma, Bond, Masuda, \& Lillis, 2006). They argued that psychological flexibility is the individual's ability to be present with all private experiences (also those that are difficult) and engage in chosen values-driven actions. The opposite of this is experiential avoidance, i.e., a tendency to escape unpleasant private events that can underlie psychopathology and poor wellbeing (Hayes et al., 2006; Hayes, Strosahl, \& Wilson, 1999). Hayes and colleagues (Hayes et al., 1999; Hayes, Strosahl, \& Wilson, 2012), also propose Acceptance and Commitment Therapy (ACT) to be an approach aimed at decreasing experiential avoidance and increasing psychological flexibility; this involves noticing and allowing all private experiences (pleasant or unpleasant) to be as they are, in order to engage in meaningful actions. These ACT interventions have been proven to be beneficial for individuals with a variety of mental disorders, health problems, and addictions (A-Tjak et al., 2015; Ruiz, 2010), including smoking (for a review, see McCallion \& Zvolensky, 2015) using various methods of delivery, such as online and mobile interventions (for a review, see Brown, Glendenning, Hoon, \& John, 2016). McCallion and Zvolensky (2015) reviewed current results on the efficacy of ACT for smoking cessation and concluded that treating smoking-specific experiential avoidance may be an important mechanism for change. Furthermore, there is considerable evidence supporting the importance of experiential avoidance in smoking maintenance and relapse (Farris et al., 2016; Minami, Bloom, Reed, Hayes, \& Brown, 2015; Zvolensky, Farris, Schmidt, \& Smits, 2014).

Both mindfulness as well as psychological flexibility seem closely related to impulsivity and risk aversion as defined in behavioral economics. All of the four concepts are related to a focus on the present moment, although in different ways (Ashe, Newman, \& Wilson, 2015). Mindfulness and psychological flexibility imply nonjudgmental acceptance of the ongoing experience, which includes those experiences that are distressing, whereas impulsivity and risk aversion are related to an intolerance of the discomfort derived from the necessity to opt for larger, but more delayed or less certain rewards.

\section{Mindfulness and psychological flexibility in discounting}

Conclusions from previous research support the supposition that interventions based on both mindfulness and psychological flexibility can alter delay and probability discounting rates in individuals. Mindfulness-based interventions aim to train the individual's ability to detect enticement cues and flexibly switch attention in ways that support self-control. Researchers hypothesize that a nonjudgmental, de-centered approach also allows an individual to approach enticements as purely mental events and hence to take a more effective action in response to cravings (van Dillen \& Papies, 2016).

So far, existing research support this hypothesis. Mindfulness-based training applied to five participants with ADHD using a multiple-probe experimental design led to less impulsive decisions toward monetary outcomes (Enoch, 2015). Reality therapy and mindfulness meditation decreased delay discounting in young adults with internetgaming disorder, compared to healthy controls (Yao et al., 2017). In addition, brief mindfulness-based interventions (mindful eating) used in a group of obese individuals have shown efficacy in reducing delay and probability discounting of food items, but not money (Hendrickson \& Rasmussen, 2013). Mindfulness training for individuals with borderline personality disorder also proved to be effective in improving their ability to delay gratification, as measured by delay discounting, but not impulsivity as a trait or response inhibition (Soler et al., 2016).

However, one study with a multiple-baseline design across five participants showed mixed results of the impact of brief mindfulness exercises on impulsivity. Some participants displayed decreased discounting, although it remained the same in others or increased posttreatment (McPherson, 2015). Results from studies on mind-wandering and distraction techniques suggest that mind wandering can at times decrease delay discounting (Smallwood, Ruby, \& Singer, 2013), while distraction techniques can be helpful in coping with cravings. Ashe and colleagues (2015) discussed such confounding results with regard to substance use and proposed an explanation. The authors argue that even if mindfulness-based techniques are helpful in managing cravings without acting on them, in individuals with high delay discounting who experience strong cravings, mindfulness strategies are not sufficient and distraction becomes more powerful. However, because distraction techniques are ineffective in the long term, they propose combining both in treatment and use distraction techniques at the beginning (especially in the moments of strong temptation) and then to introduce mindfulness techniques.

In this case ACT provides a useful approach by complementing mindfulness skills with behavioral interventions that focus on commitment and values. It may 
strengthen the effects of the intervention and aid in coping with powerful enticements. Effectively, the individual becomes more aware of an enticement and the experience of craving, enabling them to step back to notice the internal experiences and to reflect on important values in order to choose an action that leads towards meaningful goals - instead of acting on a temptation (Hayes, Strosahl et al., 2012). Psychological flexibility is closely linked with perspective taking and the ability to look at oneself from a future-self perspective, which may result in decreased discounting of delayed outcomes (Macrae et al., 2016). The lack of psychological flexibility, and thus greater experiential avoidance, correlates with impulsiveness (Berghoff, Pomerantz, Pettibone, Segrist, \& Bedwell, 2012). One study involving undergraduates demonstrated that greater experiential avoidance (lower psychological flexibility) resulted in an increase in the choice to receive three electric shocks following a delay, rather than one shock immediately, which indicates increased impulsivity in the domain of losses (Salters-Pedneault \& Diller, 2013). Brief ACT training (60 to 90 minute sessions), that focused on promoting healthy decision making by training participants to observe emotions and to learn to act on values, rather than feelings, led to decreased delay discounting (Morrison, Madden, Odum, Friedel, \& Twohig, 2014). On the other hand, ACT-based intervention applied to individuals with severe psychological problems, and targeting specific problem behaviors related to impulsive decision making and failed to decrease delayed discounting, when compared to a control group; however, it did help with reducing given problem behaviors (Morrison, 2016). To summarize, conclusions regarding the effectiveness of interventions based on mindfulness and psychological flexibility are promising, yet require further investigation.

\section{Aim of the study}

Further research is needed on the interplay of smoking, mindfulness, and psychological flexibility, as well as impulsivity and the perception of risk (indexed by delay and probability discounting, respectively). Therefore, we aim to investigate whether a higher behavioral profile, composed of mindfulness and psychological flexibility, can support the regulation of impulsivity and risk aversion in smokers as shown by lower delay and probability discounting rates in those who fall within a higher behavioral profile of mindfulness and psychological flexibility. Based on theory and previous findings, we predict lower delay discounting in smokers with a higher behavioral profile of mindfulness and psychological flexibility compared to those with a lower profile, and we aim to determine the effect of a higher profile on individual probability discounting rate.

\section{Methods and materials}

\section{Participants}

A total of 195 participants were recruited from the general population (97 female and 98 male; $38.3 \pm 11.3$ years, mean age \pm SD) to participate in the study. All procedures were implemented in accordance with the local ethics committee regulations. Individual informed consent was obtained from all participants, as well as basic sociodemographic and smoking status information. Of all the participants, 140 (67 female and 73 male; $37.3 \pm 11.1$ years, mean age \pm SD) were included in further analysis, after excluding 55 participants due to missing values in any measure or nonsystematic delay or probability discounting. As advised by Johnson and Bickel (2008), discounting was assumed to be systematic if each subsequent value discounted by an increase in delay time or probability of obtaining a reward was not greater by more than $20 \%$ of the preceding value, and the value discounted by the last delay time or probability of receiving a reward was not greater than that discounted by the first (for more details on indifference points, see measures and analysis section). With regard to a smoking status, smokers were defined as those who had maintained the smoking habit for at least a one year prior to participation. In fact, the median time of smoking prior to the study was 186 months with a median of 20 cigarettes smoked per day.

\section{Procedure}

The present study involved two parts. After informed consent was received from all participants, part one consisted of two discounting tasks, completed by each participant, one for delayed and one for probabilistic hypothetical monetary payoffs. In part two, we collected measures of mindfulness and psychological flexibility from all participants. For the discounting tasks, we used a standard discounting method, proposed by Rachlin, Raineri, and Cross (1991). Two fixed choice procedure tasks with titrating values were employed in pen-andpaper format to measure individual delay and probability discounting rates, one for delay and one for probability conditions. We used one reward magnitude of PLN 1400 and PLN 1200 for delay and probability discounting, respectively (1 Polish Zloty [PLN] equaled approximately USD 0.20 at the time of the study). The reward value differed between the conditions to avoid carry-over effects between the two conditions. Four delay times (1 month, 6 months, 1 year, and 5 years) and four probabilities $(95 \%, 75 \%, 50 \%$, and $25 \%)$ of obtaining a reward were used. Each task featured two columns of rows with corresponding payoff alternatives: immediate or certain and delayed or probabilistic, in delay and probability discounting conditions, respectively. Rows in the left column (column A) contained the immediate or certain alternatives, and the right column (column B) contained the corresponding delayed or probabilistic alternatives. The values of the immediate or certain alternatives in column A were presented over the rows in descending order in 23 decrements, while keeping the value of the corresponding delayed or probabilistic alternative at a constant nominal value (PLN 1400 in the delay condition and PLN 1200 in the probability condition). Participants had to indicate their preferred alternative in each row. Each condition of delay time or probability of receiving a reward was presented on 
a separate page. All tasks were presented to participants in a counterbalanced order.

Subsequent to the main procedure, participants completed the Philadelphia Mindfulness Scale (PHLMS; Cardaciotto, Herbert, Forman, Moitra, \& Farrow, 2008) and the Acceptance and Action Questionnaire 2 (AAQ2; Bond et al., 2011). The first measure, PHLMS, is a 20 item self-report measure with each item consisting of a statement to be rated on a 5-point Likert-type scale. The PHLMS includes two subscales and higher scores obtained in each indicates higher mindful presentmoment awareness (MAW) and higher nonjudgemental acceptance (MAC). The second measure, AAQ2 contained seven statements related to contacting difficult inner experiences in order to engage in valued activities. Each statement was rated on a 7-point Likert-type scale that indicated the individual convergence with its content. A higher score obtained in AAQ2 corresponded to a higher psychological flexibility, defined as the ability to engage in meaningful actions even in the presence of difficult internal experiences.

\section{Measures and analysis}

In preliminary analysis we aimed to categorize participants based on their mindfulness and psychological flexibility score. To partition individuals into behavioral profiles based on the score in PHLMS, separately for the MAW and MAC subscales, and AAQ2, a $k$-means cluster analysis was performed. We aimed to maximize the interpretability of the number of clusters obtained, as suggested by Cross (2013), while also maintaining formal validity of the clustering solution. Therefore, the optimal clustering solution was explored and confirmed independently with three prominent clustering validity indexes: the CalińskiHarabasz index (CH; Caliński \& Harabasz, 1974), Gap statistic (Gap; Tibshirani, Walther, \& Hastie, 2001), and average silhouette width ( $S$; Rousseeuw, 1987).

The delay and probability discounting procedures employed here aim to estimate the indifference points, i.e., certain or immediate values approximately subjectively equal to probabilistic or delayed outcomes for given delays or the probabilities of receiving a reward. The indifference points were defined as the value of the last payoff chosen in column A before the preference switched to the alternatives in column B. This last chosen value in column A represents the approximate subjective value of a delayed or probabilistic payoff with a given delay time or probability of receiving it. To infer the appropriate discounting rates, we have used the area under the curve measure (AUC), as suggested by Myerson and colleagues (2001). This was computed as the area under the line segments that connect each indifference point obtained in delay and probability discounting for each delay time or probability (as expressed by odds against) of receiving a reward. A higher value of the AUC is interpreted as a lower discounting rate. In other words, the closer the AUC is to unity, the slower or shallower the discounting rate, showing less preference for immediacy (in delay discounting) or less preference for certainty (in probability discounting). To determine the relationship of the behavioral profile and smoking status on the discounting rate, we used a $2 \times 2$ between-subjects factorial model of analysis (Two-Way ANOVA) separately for AUC measures obtained from delay and probability discounting. Sidak's significance correction for multiple comparisons was applied to the analysis of simple effects in further inferences.

\section{Results}

In the preliminary analysis, the optimal number of clusters $k$, based on MAW, MAC, and AAQ2 values, was established as $k=2$. This clustering solution yields superior values in $\mathrm{CH}$, Gap, and $S$ indexes, compared to the neighboring solutions of up to 5 clusters (Table 1). Following the approach outlined by Cross (2013); we decided to adopt this solution due to the maximized interpretability of the resulting clusters, despite it achieving relatively modest values in the three indexes. Index values for the neighboring solutions can be found in Table 1 .

Table 1. Values of the 3 cluster validity indexes $(\mathrm{CH}, \mathrm{Gap}$, and $S)$, obtained for the optimal $(k=2)$ and neighboring clustering solutions (expressed as the number of clusters $k$ )

\begin{tabular}{lcccc}
\hline \multirow{2}{*}{$\begin{array}{c}\text { Clustering validity } \\
\text { index }\end{array}$} & \multicolumn{4}{c}{ Clustering solution $(\boldsymbol{k})$} \\
\cline { 2 - 5 } & $\mathbf{2}$ & $\mathbf{3}$ & $\mathbf{4}$ & $\mathbf{5}$ \\
\hline $\mathrm{CH}$ & 80.92 & 67.96 & 61.01 & 55.54 \\
\hline Gap & -0.22 & -0.76 & -1.23 & -1.43 \\
\hline$S$ & 0.33 & 0.28 & 0.25 & 0.23 \\
\hline
\end{tabular}

Two behavioral profiles of participants were isolated: the first group, hiMF-AAQ2, with higher observed MAW, MAC, and AAQ2 scores, and the second group, loMF-AAQ2, who obtained lower scores. Significant differences in MAW, MAC, and AAQ2 scores were confirmed between resulting clusters (MAW: $t(138)=2.828$; $p=.005 ; d=0.51 ;$ MAC: $t(138)=7.012 ; p<.001$; $d=1.25$, AAQ2: $t(138)=16.006 ; p<.001 ; d=2.71)$. То summarize, individuals in the hiMF-AAQ2 profile group displayed significantly higher scores in MAW, MAC, and AAQ2, corresponding to higher overall mindfulness and psychological flexibility, compared to the loMF-AAQ2 profile with lower overall mindfulness and psychological flexibility. Group composition and values of MAW, MAC, and AAQ2 in the two behavioral profiles are presented in Table 2.

Preliminary analysis was concluded by ruling out the possible confounding of the relationship between smoking status and behavioral profile. We have confirmed that there were no differences in MAW, MAC, and AAQ2 scores between smoking and nonsmoking individuals $(t(138)=0.882 ; p=.379 ; d=0.15, t(138)=1.046 ; p=.297$; $d=0.18, t(138)=.471 ; p=.638 ; d=0.08)$. 
Table 2. Characteristics and group composition of behavioral profiles partitioned by $k$-means cluster analysis

\begin{tabular}{|c|c|c|c|c|c|c|c|c|c|c|c|c|}
\hline \multirow{2}{*}{ Variable } & \multicolumn{2}{|c|}{ Sex } & \multicolumn{2}{|c|}{ Age } & \multicolumn{2}{|c|}{ Smoking } & \multicolumn{2}{|c|}{ MAW } & \multicolumn{2}{|c|}{ MAC } & \multicolumn{2}{|c|}{ AAQ2 } \\
\hline & $n$ male & $n$ female & mean & SD & $n$ yes & $n$ no & mean & SD & mean & SD & mean & SD \\
\hline hi MF-AAQ2 & 47 & 40 & 35.34 & 9.91 & 41 & 46 & 35.52 & 7.23 & 33.83 & 5.37 & 42.40 & 4.37 \\
\hline lo MF-AAQ2 & 26 & 27 & 40.42 & 12.31 & 23 & 30 & 32.23 & 5.66 & 27.68 & 4.42 & 29.02 & 5.44 \\
\hline
\end{tabular}

Note. hi MF-AAQ2, higher behavioral profile of mindfulness and psychological flexibility; lo MF-AAQ2, lower behavioral profile of mindfulness and psychological flexibility; MAW, mindful present-moment awareness subscale (of the PHLMS, Philadelphia Mindfulness Scale); MAC, nonjudgemental acceptance subscale (of the PHLMS, Philadelphia Mindfulness Scale); AAQ2, Acceptance and Action Questionnaire 2.

\section{Discounting of delayed rewards}

In the main analysis, we observed a significant main effect of the behavioral profile in delay discounting $\left(F(1,136)=8.145 ; p=.005 ; \eta_{\mathrm{p}}^{2}=.057\right)$, which signifies that overall, the loMF-AAQ2 profile group discounted rewards steeper $(M=0.53, S D=0.26)$ than the hiMF-AAQ2 group $(M=0.6288, S D=0.21)$. In parallel, there was no statistically significant main effect of smoking status $(F(1,136)=2.023$; $\left.p=.157 ; \eta_{\mathrm{p}}^{2}=.015\right)$. We did, however, observe a significant interaction effect of behavioral profile and smoking status $\left(F(1,136)=9.182 ; p=.003 ; \eta_{\mathrm{p}}^{2}=.063\right)$, and therefore we examined the structure of simple effects. In relation to smoking status, we found that among smokers, the loMF-AAQ2 profile group showed higher discounting than the hiMF-AAQ2 group $(M=0.43, S D=0.23$ vs $M=0.66$, $S D=0.20$ for loMF-AAQ2 and hiMF-AAQ2, respectively) $(p<.001)$. No such differences between the two groups were found in the nonsmoking subgroup $(\mathrm{M}=0.61, \mathrm{SD}=0.27$ vs $\mathrm{M}=0.60, \mathrm{SD}=0.22$ for loMF-AAQ2 and hiMF-AAQ2, respectively) $(p=.895)$. Furthermore, we found that in the hiMF-AAQ2 profile group there were no significant differences in discounting rates between smokers and nonsmokers $(p=.192)$. Importantly, in the loMF-AAQ2 profile, smokers discounted delayed rewards more steeply than the nonsmoker group $(p=.006)$.

\section{Discounting of probabilistic rewards}

For probability discounting, as with the delay condition, there was a main effect of the behavioral profile

group $\left(F(1,136)=12.179 ; p=.001 ; \eta_{\mathrm{p}}^{2}=.082\right)$. No effect of smoking status $\left(F(1,136)=1.400 ; p=.239 ; \eta_{\mathrm{p}}^{2}=.010\right)$ or its interaction with the behavioral profile $(F(1,136)=0.677$; $\left.p=.412 ; \eta_{\mathrm{p}}^{2}=.005\right)$ was observed, however. With respect

Figure 2. Median indifference points in smokers and nonsmokers for the loMF-AAQ2 and hiMF-AAQ2 profile groups (Panel A) obtained in the probability discounting condition, with corresponding mean values of the AUC for the two behavioral profiles (Panel B). Results were collapsed for smokers and nonsmokers, due to the absence of a main effect of smoking status or its interaction with the behavioral profile; loMF-AAQ2, lower behavioral profile of mindfulness and psychological flexibility; hiMF-AAQ2, higher behavioral profile of mindfulness and psychological flexibility.

(A)

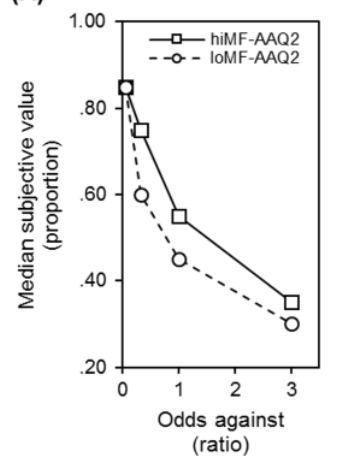

(B)

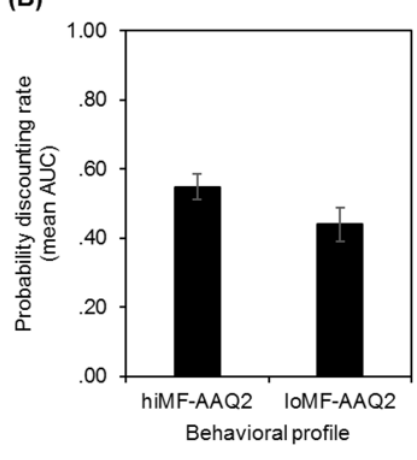

Figure 1. Median indifference points in smokers and nonsmokers for the loMF-AAQ2 and hiMF-AAQ2 profile groups (Panel A) obtained in the delay discounting condition, with corresponding mean values of the AUC that demonstrates the interaction between smoking status and behavioral profile on delay discounting (Panel B); S, smokers; nS, nonsmokers; loMF-AAQ2, lower behavioral profile of mindfulness and psychological flexibility; hiMF-AAQ2, higher behavioral profile of mindfulness and psychological flexibility.

(A)

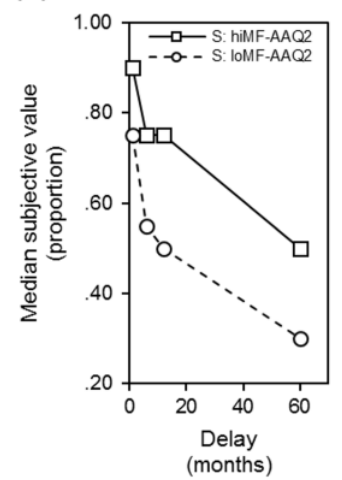

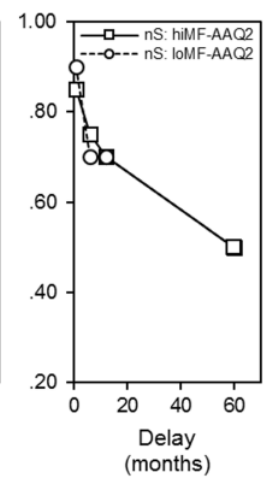

(B)

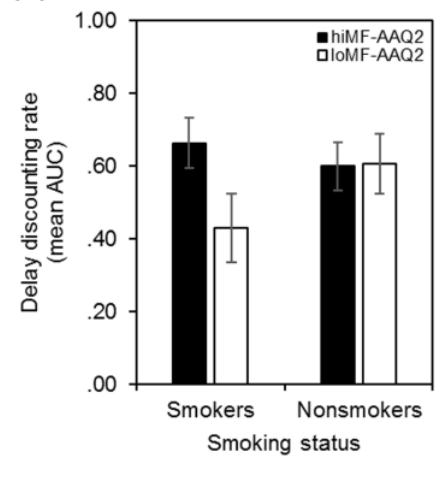


to the discounting rate between loMF-AAQ2 and hiMF-AAQ2 groups, a higher rate of discounting was again found in the loMF-AAQ2 group $(M=0.44, S D=0.15)$, compared to the hiMF-AAQ2 group $(M=0.55, S D=0.19)$ $(p=.001)$. Unlike in the delay discounting condition, smoking status did not further differentiate the rate at which the participants discounted probabilistic rewards in the two behavioral profile groups.

\section{Discussion}

We investigated the impact in smokers of a higher or lower behavioral profile of mindfulness and psychological flexibility on delay and probability discounting (proxies of impulsivity and risk aversion, respectively). In the preliminary analysis, participants were partitioned into two behavioral profiles: (1) those with lower mindfulness and psychological flexibility (profile loMF-AAQ2); and (2) those with higher mindfulness and psychological flexibility (profile hiMF-AAQ2). In other words, a higher profile corresponded to higher present-moment awareness, nonjudgmental acceptance of ongoing experiences, and greater psychological flexibility. The main analysis was performed to investigate the impact of the behavioral profile and smoking status on delay and probability discounting. Individuals with higher mindfulness and psychological flexibility profile showed overall lower discounting rates in delay and probability discounting tasks, compared to individuals with a lower profile. Interestingly, smoking status further differentiated the rate at which participants discounted delayed, but not probabilistic rewards. Smokers with higher scores in mindfulness and psychological flexibility discounted delayed rewards less steeply, compared to those with lower scores. However, there were no differences in delay discounting in nonsmoking individuals between groups with higher and lower mindfulness and psychological flexibility scores. For probabilistic rewards, individuals with a higher profile displayed decreased discounting, similarly to the delay condition, but regardless of smoking status.

Our results suggest that smokers who are less aware of their impulses, less accepting of them, and less able to engage in meaningful actions while those impulses are present, tend to be more impulsive. Taking into account existing evidence regarding the effectiveness of both mindfulness-based and ACT interventions in decreasing delay discounting (Enoch, 2015; Morrison et al., 2014; Yao et al., 2017), we may assume that interventions aimed at increasing mindfulness and psychological flexibility might be beneficial in decreasing impulsivity (as defined by a strong preference for immediate rewards) and may further promote smoking cessation. We propose that behavioral interventions, focused on increasing mindfulness and psychological flexibility, could prove effective in equating the delay discounting of smokers to that of nonsmoking individuals.

Present results offer a potential explanation for the efficacy of mindfulness-based and ACT interventions in regulating impulsivity in smokers. Prior research suggests mindfulness and impulsivity to be partially overlapping but distinct concepts (Murphy \& Mackillop, 2012). Therefore we suggest that high levels of mindfulness and psychological flexibility may act as a buffer towards impulsivity. Even in individuals with a tendency for more impulsive choices (coinciding with the presence of an addiction) increased awareness and acceptance of arising impulses, and an ability to enact what is more beneficial in the long term in the presence of those impulses, may lessen the negative impact of this existing tendency and enable more informed action.

Our results could also suggest that a certain subgroup of smokers would benefit more from mindfulness-based interventions. It may be that in smokers, similarly to opiatedependent individuals, there are different mechanisms leading to addiction, some related to impulsivity and others that are not (Passetti, Verdejo-Garcia, \& Abou-Saleh, 2013). This supports the hypothesis of Dakwar, Mariani, and Levin (2011), regarding substance-using groups. Some subgroups may possess more pronounced deficits in mindfulness and psychological flexibility and may benefit from interventions that target those abilities more than others.

Delay discounting could also be used as a marker for intervention choice. As suggested by Ashe and colleagues (2015), when a person submits to treatment, their level of delay discounting (that reflects susceptibility for craving) may help to guide the decision as to the most beneficial course of treatment and which intervention components would be most successful. For people with steeper discounting, mindfulness-based interventions may be more useful, whereas for people with shallower delay discounting there might be a need for interventions aimed to increase motivation, or focused on values clarification. However, as no norms for delay discounting have been identified so far (MacKillop et al., 2016), this problem needs further investigation.

In our study, we demonstrate a different relationship of delay and probability discounting and the behavioral profile. Although some theoretical approaches regard both the delay and probability discounting as reflecting the same underlying trait or process of impulsivity (Green \& Myerson, 2013; Myerson, Green, Scott Hanson, Holt, \& Estle, 2003; Rachlin, Logue, Gibbon, \& Frankel, 1986), empirical evidence shows that these processes are positively, but weakly correlated (Holt, Green, \& Myerson, 2003; Mitchell \& Wilson, 2010). Following this reasoning, an impulsive individual may choose the immediate, smaller reward, and also avoid risk and have the certainty of the small amount (Białaszek, Gaik, McGoun, \& Zielonka, 2015). Because of these discrepancies on a theoretical and empirical level, we refer to impulsivity as the choice in the intertemporal domain, and to risk aversion not as a direct facet of impulsivity, but rather a dimension that reflects the degree of probability discounting.

Participants with a higher behavioral profile of mindfulness and psychological flexibility displayed lower risk aversion, regardless of smoking status. One possible interpretation of this result is that people with higher mindfulness and psychological flexibility have a greater capacity to cope with the discomfort derived from the risk 
of whether a reward will be obtained. Such an ability may promote better enactment of individual values, working towards goals, or taking courageous action despite there being the risk of whether an anticipated outcome will occur. Our results showed that this was unrelated to smoking status, therefore it may be hypothesized to be related to a more general disposition.

Of note, our participants were classified into two profiles consisting of mindful awareness, mindful acceptance, and psychological flexibility, suggesting that being aware of inner experiences is not enough to abstain from impulsive choices and must be accompanied by acceptance of one's own experience, as well as the ability to make choices more consistent with values. On the other hand, people who have less awareness of inner experience, also have less acceptance and less psychological flexibility, which may be due to avoidance of these internal experiences (that are seen as unpleasant).

We observed that some of the smokers displayed a high behavioral profile of mindfulness and psychological flexibility, which may suggest that the relation of impulsivity and addiction is not direct. Some research suggests that impulsivity (indexed by steeper discounting) might be an etiological factor in the onset of addiction, while in other increased discounting was a result of the extended exposure to an addictive substance (for a review, see MacKillop et al., 2011). Considering that the evidence of any causal relationships of impulsivity and addiction is not sufficiently conclusive, we propose that while a higher behavioral profile of psychological flexibility and mindfulness may support better coping with impulsive behavior that coincides with addiction, it may also be that not only the urge or difficulty in tolerating ongoing emotion leads to smoking but also mindful decisions to do so, i.e., the choice to smoke due to its function of improving focus, relaxation, or inducing pleasure.

Finally, we note that our conclusions should be confirmed by future experimental data. In addition, individual smoking status was measured by self-report, and while we did check for the time since taking up smoking and its intensity, it was not controlled otherwise. We also did not control for other problem behaviors related to addiction. Interpretation of our results could also be impacted by the measures we used. The AAQ2 questionnaire is under discussion with respect to its validity (Wolgast, 2014).

The main result of the present study demonstrates that those who are more impulsive are not only individuals who smoke but also individuals with a lower level of mindfulness and psychological flexibility. In parallel, those with a high mindfulness and psychological flexibility profile are less risk-averse. Future studies may employ alternative measures of psychological flexibility, such as measures related to cognitive flexibility and values, as well as ecological momentary assessment. Nevertheless, we believe that our conclusions are promising, and that the potential benefit of mindfulness and psychological flexibility-based interventions in managing impulsivity in smokers is considerable.

\section{Acknowledgments}

Present work was funded by the National Science Centre Poland grant no. 2015/19/D/HS6/00770. We thank the members of the Behavioral Economics Research Group (BERG) at the SWPS University of Social Sciences and Humanities for valuable discussions.

\section{References}

Ainslie, G., \& Monterosso, J.R. (2003). Building blocks of self-control: increased tolerance for delay with bundled rewards. Journal of the Experimental Analysis of Behavior, 79(1), 37-48. https://doi. org/10.1901/jeab.2003.79-37

Amlung, M., Vedelago, L., Acker, J., Balodis, I., \& MacKillop, J. (2017). Steep delay discounting and addictive behavior: a meta-analysis of continuous associations. Addiction, 112(1), 51-62. https://doi. org/10.1111/add.13535

Ashe, M.L., Newman, M.G., \& Wilson, S.J. (2015). Delay discounting and the use of mindful attention versus distraction in the treatment of drug addiction: A conceptual review. Journal of the Experimental Analysis of Behavior, 103(1), 234-248. https://doi.org/10.1002/jeab.122

A-Tjak, J.G.L., Davis, M.L., Morina, N., Powers, M.B., Smits, J.A.J., \& Emmelkamp, P.M.G. (2015). A meta-analysis of the efficacy of acceptance and commitment therapy for clinically relevant mental and physical health problems. Psychotherapy and Psychosomatics, 84(1), 30-36. https://doi.org/10.1159/000365764

Barlow, P., McKee, M., Reeves, A., Galea, G., \& Stuckler, D. (2016). Time-discounting and tobacco smoking: a systematic review and network analysis. International Journal of Epidemiology. https:// doi.org/10.1093/ije/dyw233

Berghoff, C.R., Pomerantz, A.M., Pettibone, J.C., Segrist, D.J., \& Bedwell, D.R. (2012). The Relationship Between Experiential Avoidance and Impulsiveness in a Nonclinical Sample. Behaviour Change, 29(1), 25-35. https://doi.org/10.1017/bec.2012.6

Białaszek, W., Gaik, M., McGoun, E., \& Zielonka, P. (2015). Impulsive people have a compulsion for immediate gratification-certain or uncertain. Frontiers in Psychology, 6, 515. https://doi.org/10.3389/ fpsyg.2015.00515

Bickel, W.K., Koffarnus, M.N., Moody, L., \& Wilson, A.G. (2014). The behavioral- and neuro-economic process of temporal discounting: A candidate behavioral marker of addiction. Neuropharmacology, 76 Pt B, 518-527. https://doi.org/10.1016/j.neuropharm.2013.06.013

Bickel, W.K., Yi, R., Landes, R.D., Hill, P.F., \& Baxter, C. (2011). Remember the Future: Working Memory Training Decreases Delay Discounting Among Stimulant Addicts. Biological Psychiatry, 69(3), 260-265. https://doi.org/10.1016/j.biopsych.2010.08.017

Bishop, S.R., Lau, M., Shapiro, S., Carlson, L., Anderson, N.D., Carmody, J., ... \& Devins, G. (2004). Mindfulness: A proposed operational definition. Clinical psychology: Science and practice, 11(3), 230-241.

Bond, F.W., Hayes, S.C., Baer, R.A., Carpenter, K.M., Guenole, N., Orcutt, H.K., Walts, T., \& Zettle, R.D. (2011). Preliminary psychometric properties of the Acceptance and Action Questionnaire-II: a revised measure of psychological inflexibility and experiential avoidance. Behavior Therapy, 42(4), 676-688. https://doi.org/10.1016/ j.beth.2011.03.007

Bowen, S., \& Marlatt, A. (2009). Surfing the urge: brief mindfulnessbased intervention for college student smokers. Psychology of Addictive Behaviors: Journal of the Society of Psychologists in Addictive Behaviors, 23(4), 666-671. https://doi.org/10.1037/a0017127

Brewer, J.A., Mallik, S., Babuscio, T.A., Nich, C., Johnson, H.E., Deleone, C.M., ... Rounsaville, B.J. (2011). Mindfulness training for smoking cessation: results from a randomized controlled trial. Drug and Alcohol Dependence, 119(1-2), 72-80. https://doi. org/10.1016/j.drugalcdep.2011.05.027

Brown, M., Glendenning, A.C., Hoon, A.E., \& John, A. (2016). Effectiveness of Web-Delivered Acceptance and Commitment Therapy in Relation to Mental Health and Well-Being: A Systematic Review and Meta-Analysis. Journal of Medical Internet Research, 18(8), e221. https://doi.org/10.2196/jmir.6200 
Caliński, T., \& Harabasz, J. (1974). A dendrite method for cluster analysis. Communications in Statistics, 3(1), 1-27. https://doi org/10.1080/03610927408827101

Cardaciotto, L., Herbert, J.D., Forman, E.M., Moitra, E., \& Farrow, V. (2008). The assessment of present-moment awareness and acceptance: the Philadelphia Mindfulness Scale. Assessment, 15(2), 204-223. https://doi.org/10.1177/1073191107311467

Cross, C.L. (2013). Statistical and Methodological Considerations When Using Cluster Analysis in Neuropsychological Research. In: D.N. Allen, \& G. Goldstein (Eds.), Cluster Analysis in Neuropsychological Research (pp. 13-35). Springer New York. https://doi. org/10.1007/978-1-4614-6744-1_2

Cullen, M. (2011). Mindfulness-Based Interventions: An Emerging Phenomenon. Mindfulness, 2(3), 186-193. https://doi.org/10.1007/ s12671-011-0058-1

Dakwar, E., Mariani, J.P., \& Levin, F.R. (2011). Mindfulness impairments in individuals seeking treatment for substance use disorders. The American Journal of Drug and Alcohol Abuse, 37(3), 165-169. https://doi.org/10.3109/00952990.2011.553978

de Souza, I.C.W., de Barros, V.V., Gomide, H.P., Miranda, T.C.M., Menezes, V. de P., Kozasa, E.H., \& Noto, A.R. (2015). Mindfulnessbased interventions for the treatment of smoking: a systematic literature review. Journal of Alternative and Complementary Medicine (New York, N.Y.), 21(3), 129-140. https://doi.org/10.1089 acm.2013.0471

Demarzo, M.M.P., Montero-Marin, J., Cuijpers, P., Zabaleta-del-Olmo, E., Mahtani, K.R., Vellinga, A., ... García-Campayo, J. (2015). The Efficacy of Mindfulness-Based Interventions in Primary Care: A Meta-Analytic Review. The Annals of Family Medicine, 13(6), 573-582. https://doi.org/10.1370/afm.1863

van Dillen, L.F., \& Papies, E.K. (2014). From distraction to mindfulness: Psychological and neural mechanisms of attention strategies in selfregulation. In: G. Gendolla, M. Tops, \& S. Koole (Eds.), Biobehavioral Foundations of Self-Regulation (pp. 141-154) New York: Springer.

Doll, R., Peto, R., Boreham, J., \& Sutherland, I. (2004). Mortality in relation to smoking: 50 years' observations on male British doctors. $B M J, 328(7455), 1519$. https://doi.org/10.1136/bmj.38142.554479. $\mathrm{AE}$

Enoch, M. (2015). Using mindfulness to increase directed attention, selfcontrol, and psychological flexibility in children. Dissertations. Retrieved from http://opensiuc.lib.siu.edu/dissertations/1143

Ezzati, M., \& Riboli, E. (2013). Behavioral and Dietary Risk Factors for Noncommunicable Diseases. New England Journal of Medicine, 369(10), 954-964. https://doi.org/10.1056/NEJMra1203528

Farris, S.G., Zvolensky, M.J., Norton, P.J., Hogan, J., Smith, A.H., Talkovsky, A.M., Garey, L., \& Schmidt, N.B. (2016). SmokingSpecific Experiential Avoidance is Indirectly Associated with Trai Worry and Smoking Processes among Treatment-Seeking Smokers. Behavioral Medicine, 42(4), 254-263. https://doi.org/10.1080/0896 4289.2014.984650

Finucane, M.M., Stevens, G.A., Cowan, M.J., Danaei, G., Lin, J.K., Paciorek, C.J., Singh, G.M., Gutierrez, H.R., Lu, Y., Bahalim, A.N., Farzadfar, F., Riley, L.M., \& Ezzati, M. on behalf of the Global Burden of Metabolic Risk Factors of Chronic Diseases Collaborating Group (Body Mass Index). (2011). National, regional, and global trends in body-mass index since 1980: systematic analysis of health examination surveys and epidemiological studies with 960 countryyears and $9 \cdot 1$ million participants. Lancet, 377(9765), 557-567. https://doi.org/10.1016/S0140-6736(10)62037-5

Gray, J.C., \& MacKillop, J. (2015). Impulsive delayed reward discounting as a genetically-influenced target for drug abuse prevention: a critical evaluation. Frontiers in Psychology, 6, 1104. https://doi. org/10.3389/fpsyg.2015.01104

Green, L., \& Myerson, J. (2013). How many impulsivities? A discounting perspective. Journal of the Experimental Analysis of Behavior, 99(1), 3-13. https://doi.org/10.1002/jeab.1

Hayes, S.C., Barnes-Holmes, D., \& Wilson, K.G. (2012). Contextual Behavioral Science: Creating a science more adequate to the challenge of the human condition. Journal of Contextual Behavioral Science, 1(1-2), 1-16. https://doi.org/10.1016/j.jcbs.2012.09.004

Hayes, S.C., Levin, M.E., Plumb-Vilardaga, J., Villatte, J.L., \& Pistorello, J. (2013). Acceptance and Commitment Therapy and Contextual
Behavioral Science: Examining the Progress of a Distinctive Model of Behavioral and Cognitive Therapy. Behavior Therapy, 44(2), 180-198. https://doi.org/10.1016/j.beth.2009.08.002

Hayes, S.C., Luoma, J.B., Bond, F.W., Masuda, A., \& Lillis, J. (2006) Acceptance and commitment therapy: model, processes and outcomes. Behaviour Research and Therapy, 44(1), 1-25. https://doi. org/10.1016/j.brat.2005.06.006

Hayes, S.C., Strosahl, K.D., \& Wilson, K.G. (1999). Acceptance and Commitment Therapy: An Experiential Approach to Behavior Change (1 edition). New York: The Guilford Press.

Hayes, S.C., Strosahl, K.D., \& Wilson, K.G. (2012). Acceptance and Commitment Therapy, Second Edition: The Process and Practice of Mindful Change (2 edition). The Guilford Press.

Hendrickson, K.L., \& Rasmussen, E.B. (2013). Effects of mindful eating training on delay and probability discounting for food and money in obese and healthy-weight individuals. Behaviour Research and Therapy, 51(7), 399-409. https://doi.org/10.1016/j. brat.2013.04.002

Holt, D.D., Green, L., \& Myerson, J. (2003). Is discounting impulsive?. Evidence from temporal and probability discounting in gambling and nongambling college students. Behavioural Processes, 64(3), 355-367.

Jha, P., \& Peto, R. (2014). Global Effects of Smoking, of Quitting, and of Taxing Tobacco. New England Journal of Medicine, 370(1), 60-68. https://doi.org/10.1056/NEJMra1308383

Jha, P., Ramasundarahettige, C., Landsman, V., Rostron, B., Thun, M., Anderson, R.N., McAfee, T., \& Peto, R. (2013). 21st-century hazards of smoking and benefits of cessation in the United States. The New England Journal of Medicine, 368(4), 341-350. https://doi. org/10.1056/NEJMsa1211128

Johnson, M.W., \& Bickel, W.K. (2008). An algorithm for identifying nonsystematic delay-discounting data. Experimental and Clinical Psychopharmacology, 16(3), 264-274. https://doi.org/10.1037/10641297.16.3.264

Krishnan-Sarin, S., Reynolds, B., Duhig, A.M., Smith, A., Liss, T., McFetridge, A., Cavallo, D.A., Carroll, K.M., \& Potenza, M.N. (2007). Behavioral impulsivity predicts treatment outcome in a smoking cessation program for adolescent smokers. Drug and Alcohol Dependence, 88(1), 79-82. https://doi.org/10.1016/j.drugalcdep.2006.09.006

Lim, S.S., Vos, T., Flaxman, A.D., Danaei, G., Shibuya, K., Adair-Rohani, H., ... Ezzati, M. (2012). A comparative risk assessment of burden of disease and injury attributable to 67 risk factors and risk factor clusters in 21 regions, 1990-2010: a systematic analysis for the Global Burden of Disease Study 2010. The Lancet, 380(9859), 2224-2260. https://doi.org/10.1016/S0140-6736(12)61766-8

Logue, A.W. (1988). Research on self-control: An integrating framework. Behavioral and Brain Sciences, 11(4), 665-679. https://doi. org/10.1017/S0140525X00053978

López-Torrecillas, F., Nieto-Ruiz, A., Velasco-Ortuño, S., Lara-Fernández, M., López-Quirantes, E.M., \& Castillo-Fernández, E. (2014). The role of impulsivity in dropout from treatment for cigarette smoking. Comprehensive Psychiatry, 55(7), 1609-1613. https://doi. org/10.1016/j.comppsych.2014.06.004

MacKillop, J., Amlung, M.T., Few, L.R., Ray, L.A., Sweet, L.H., \& Munafo, M.R. (2011). Delayed reward discounting and addictive behavior: a meta-analysis. Psychopharmacology, 216(3), 305-321. https://doi.org/10.1007/s00213-011-2229-0

MacKillop, J., Amlung, M.T., Wier, L.M., David, S.P., Ray, L.A., Bickel, W.K., \& Sweet, L.H. (2012). The neuroeconomics of nicotine dependence: a preliminary functional magnetic resonance imaging study of delay discounting of monetary and cigarette rewards in smokers. Psychiatry Research, 202(1), 20-29. https://doi.org/10.1016/j.pscychresns.2011.10.003

MacKillop, J., \& Kahler, C.W. (2009). Delayed reward discounting predicts treatment response for heavy drinkers receiving smoking cessation treatment. Drug and Alcohol Dependence, 104(3), 197-203. https://doi.org/10.1016/j.drugalcdep.2009.04.020

MacKillop, J., Weafer, J., Gray, J.C., Oshri, A., Palmer, A., \& Wit, H. de. (2016). The latent structure of impulsivity: impulsive choice, impulsive action, and impulsive personality traits. Psychopharmacology, 233(18), 3361-3370. https://doi.org/10.1007/s00213-016-4372-0

Macrae, C.N., Mitchell, J.P., Golubickis, M., Ho, N.S.P., Sherlock, R., Parlongo, R., Simpson, O.C.M., \& Christian, B.M. (2016). Saving for 
your future self: The role of imaginary experiences. Self and Identity, O(0), 1-15. https://doi.org/10.1080/15298868.2016.1264465

Madden, G.J., \& Johnson, P.S. (2010). A delay-discounting primer. In: G.J. Madden, W.K. Bickel, \& T.S. Critchfield (Eds.), Impulsivity: The behavioral and neurological science of discounting (pp. 11-37). Washington, DC: American Psychological Association.

Marlatt, G.A. (2002). Buddhist philosophy and the treatment of addictive behavior. Cognitive and Behavioral Practice, 9(1), 44-50. https:// doi.org/10.1016/S1077-7229(02)80039-6

Mazur, J.E. (1987). An adjusting procedure for studying delayed reinforcement. In: M.L. Commons, J.E. Mazur, J.A. Nevin, \& H. Rachlin (Eds.). Quantitative analysis of behavior: Vol. 5. The effect of delay and of intervening events of reinforcement value. Hillsdale, NJ: Erlbaum, pp. 55-73.

McCallion, E.A., \& Zvolensky, M.J. (2015). Acceptance and Commitment Therapy (ACT) for smoking cessation: a synthesis. Current Opinion in Psychology, 2, 47-51. https://doi.org/10.1016/j.copsyc.2015.02.005

McPherson, S.K. (2015). The effect of brief mindfulness exercises on momentary impulsivity. Southern Illinois University at Carbondale. Retrieved from http://gradworks.umi.com/16/03/1603290.html

Minami, H., Bloom, E.L., Reed, K.M.P., Hayes, S.C., \& Brown, R.A. (2015). The moderating role of experiential avoidance in the relationships between internal distress and smoking behavior during a quit attempt. Psychology of Addictive Behaviors: Journal of the Society of Psychologists in Addictive Behaviors, 29(2), 400-407. https://doi.org/10.1037/adb0000030

Mitchell, S.H. (1999). Measures of impulsivity in cigarette smokers and non-smokers. Psychopharmacology, 146(4), 455-464.

Mitchell, S.H. (2004). Effects of short-term nicotine deprivation on decision-making: Delay, uncertainty and effort discounting. Nicotine \& Tobacco Research, 6(5), 819-828. https://doi.org/10.1080/1462220 0412331296002

Mitchell, S.H., \& Wilson, V.B. (2010). The subjective value of delayed and probabilistic outcomes: Outcome size matters for gains but not for losses. Behavioural Processes, 83(1), 36-40. https://doi. org/10.1016/j.beproc.2009.09.003

Morrison, K. (2016). Effects of Acceptance and Commitment Therapy on Impulsive Decision Making. All Graduate Theses and Dissertations. Retrieved from http://digitalcommons.usu.edu/etd/5069

Morrison, K.L., Madden, G.J., Odum, A.L., Friedel, J.E., \& Twohig, M.P. (2014). Altering Impulsive Decision Making With an AcceptanceBased Procedure. Behavior Therapy, 45(5), 630-639. https://doi. org/10.1016/j.beth.2014.01.001

Murphy, C., \& Mackillop, J. (2012). Living in the here and now: interrelationships between impulsivity, mindfulness, and alcohol misuse. Psychopharmacology, 219(2), 527-536. https://doi.org/10.1007/ s00213-011-2573-0

Murphy, J.G., Dennhardt, A.A., Skidmore, J.R., Borsari, B., Barnett, N.P., Colby, S.M., \& Martens, M.P. (2012). A randomized controlled trial of a behavioral economic supplement to brief motivational interventions for college drinking. Journal of Consulting and Clinical Psychology, 80(5), 876-886. https://doi.org/10.1037/ a0028763

Myerson, J., Green, L., Scott Hanson, J., Holt, D.D., \& Estle, S.J. (2003). Discounting delayed and probabilistic rewards: Processes and traits. Journal of Economic Psychology, 24(5), 619-635. http://doi org/10.1016/S0167-4870(03)00005-9

Myerson, J., Green, L., \& Warusawitharana, M. (2001). Area under the curve as a measure of discounting. Journal of the Experimental Analysis of Behavior, 76(2), 235-243. http://doi.org/10.1901/ jeab.2001.76-235

Odum, A.L. (2011). Delay discounting: I'mak, you'reak. Journal of the Experimental Analysis of Behavior, 96(3), 427-439. https://doi. org/10.1901/jeab.2011.96-423

Ohmura, Y., Takahashi, T., \& Kitamura, N. (2005). Discounting delayed and probabilistic monetary gains and losses by smokers of cigarettes. Psychopharmacology, 182(4), 508-515. https://doi. org $/ 10.1007 / \mathrm{s} 00213-005-0110-8$

Passetti, F., Verdejo-Garcia, A., \& Abou-Saleh, M. (2013). Comparatively preserved impulse control in late-onset opiate users. Psychopharmacology, 230(3), 499-505. https://doi.org/10.1007/s00213-0133174-x
Peysakhovich, A. (2014). How to commit (if you must): Commitment contracts and the dual-self model. Journal of Economic Behavior \& Organization, 101, 100-112. https://doi.org/10.1016/j.jebo.2014.02.003

Pirie, K., Peto, R., Reeves, G.K., Green, J., \& Beral, V. (2013). The 21st century hazards of smoking and benefits of stopping: a prospective study of one million women in the UK. The Lancet, 381(9861), 133-141. https://doi.org/10.1016/S0140-6736(12)61720-6

Plaza, I., Demarzo, M.M.P., Herrera-Mercadal, P., \& García-Campayo, J. (2013). Mindfulness-Based Mobile Applications: Literature Review and Analysis of Current Features. JMIR mHealth and uHealth, 1(2), e24. https://doi.org/10.2196/mhealth.2733

Rachlin, H., Logue, A.W., Gibbon, J., \& Frankel, M. (1986). Cognition and behavior in studies of choice. Psychological Review, 93(1), 33.

Rachlin, H., Raineri, A., \& Cross, D. (1991). Subjective probability and delay. Journal of the Experimental Analysis of Behavior, 55, 233-244.

Read, D., Loewenstein, G., \& Rabin, M. (1999). Choice Bracketing. Journal of Risk and Uncertainty, 19(1-3), 171-197. https://doi. org/10.1023/A:1007879411489

Reynolds, B., Karraker, K., Horn, K., \& Richards, J.B. (2003). Delay and probability discounting as related to different stages of adolescent smoking and non-smoking. Behavioural Processes, 64(3), 333-344.

Reynolds, B., Richards, J.B., Horn, K., \& Karraker, K. (2004). Delay discounting and probability discounting as related to cigarette smoking status in adults. Behavioural Processes, 65(1), 35-42.

Roemer, L., Williston, S.K., \& Rollins, L.G. (2015). Mindfulness an emotion regulation. Current Opinion in Psychology, 3, 52-57. https://doi.org/10.1016/j.copsyc.2015.02.006

Rousseeuw, P.J. (1987). Silhouettes: A graphical aid to the interpretation and validation of cluster analysis. Journal of Computational and Applied Mathematics, 20, 53-65. https://doi.org/10.1016/03770427(87)90125-7

Ruiz, F.J. (2010). A Review of Acceptance and Commitment Therapy (ACT) Empirical Evidence: Correlational, Experimental Psychopathology, Component and Outcome Studies. Revista Internacional de Psicología y Terapia Psicológica, 10(1), 125-162.

Ruscio, A.C., Muench, C., Brede, E., \& Waters, A.J. (2016). Effect of Brief Mindfulness Practice on Self-Reported Affect, Craving, and Smoking: A Pilot Randomized Controlled Trial Using Ecological Momentary Assessment. Nicotine \& Tobacco Research: Official Journal of the Society for Research on Nicotine and Tobacco, 18(1), 64-73. https://doi.org/10.1093/ntr/ntv074

Salters-Pedneault, K. \& Diller, J.W. (2013). A Preliminary Study of Anxiety, Negative Affect, Experiential Avoidance, and Delaying of Aversive Events. Behaviour Change, 30(4), 241-248. https://doi. $\operatorname{org} / 10.1017 /$ bec. 2013.23

Shead, N.W., \& Hodgins, D.C. (2009). Probability discounting of gain and losses: Implications for risk attitudes and impulsivity. Journal of the Experimental Analysis of Behavior, 92(1), 1-16.

Sheffer, C.E., Christensen, D.R., Landes, R., Carter, L.P., Jackson, L., \& Bickel, W.K. (2014). Delay discounting rates: A strong prognostic indicator of smoking relapse. Addictive Behaviors, 39(11), 1682-1689. https://doi.org/10.1016/j.addbeh.2014.04.019

Smallwood, J., Ruby, F.J.M., \& Singer, T. (2013). Letting go of the present: mind-wandering is associated with reduced delay discounting Consciousness and Cognition, 22(1), 1-7. https://doi.org/10.1016/ j.concog.2012.10.007

Soler, J., Elices, M., Pascual, J.C., Martín-Blanco, A., Feliu-Soler, A., Carmona, C., \& Portella, M.J. (2016). Effects of mindfulness training on different components of impulsivity in borderline personality disorder: results from a pilot randomized study. Borderline Personality Disorder and Emotion Dysregulation, 3, 1. https://doi. org/10.1186/s40479-015-0035-8

Spijkerman, M.P.J., Pots, W.T.M., \& Bohlmeijer, E.T. (2016). Effectiveness of online mindfulness-based interventions in improving mental health: A review and meta-analysis of randomised controlled trials Clinical Psychology Review, 45, 102-114. https://doi.org/10.1016/ j.cpr.2016.03.009

Teasdale, J.D., Segal, Z., \& Williams, J.M. (1995). How does cognitive therapy prevent depressive relapse and why should attentional control (mindfulness) training help? Behaviour Research and Therapy, $33(1), 25-39$. 
Thun, M.J., Carter, B.D., Feskanich, D., Freedman, N.D., Prentice, R., Lopez, A.D., Hartge, P., \& Gapstur, S.M. (2013). 50-year trends in smoking-related mortality in the United States. The New England Journal of Medicine, 368(4), 351-364. https://doi.org/10.1056/ NEJMsa1211127

Tibshirani, R., Walther, G., \& Hastie, T. (2001). Estimating the number of clusters in a data set via the gap statistic. Journal of the Royal Statistical Society: Series B (Statistical Methodology), 63(2), 411-423. https://doi.org/10.1111/1467-9868.00293

Wolgast, M. (2014). What does the Acceptance and Action Questionnaire (AAQ-II) really measure? Behavior Therapy, 45(6), 831-839. https://doi.org/10.1016/j.beth.2014.07.002

Yao, Y.-W., Chen, P.-R., Li, C.R., Hare, T.A., Li, S., Zhang, J.-T., Liu, L., Ma, S.-S., \& Fang, X.-Y. (2017). Combined reality therapy and mindfulness meditation decrease intertemporal decisional impulsivity in young adults with Internet gaming disorder. Computers in Human Behavior, 68, 210-216. https://doi.org/10.1016/ j.chb.2016.11.038
Yi, R., \& Landes, R.D. (2012). Temporal and probability discounting by cigarette smokers following acute smoking abstinence. Nicotine \& Tobacco Research: Official Journal of the Society for Research on Nicotine and Tobacco, 14(5), 547-558. https://doi.org/10.1093/ntr/ntr252

Yoon, J.H., Higgins, S.T., Heil, S.H., Sugarbaker, R.J., Thomas, C.S., \& Badger, G.J. (2007). Delay discounting predicts postpartum relapse to cigarette smoking among pregnant women. Experimental and Clinical Psychopharmacology, 15(2), 176-186. https://doi. org/10.1037/1064-1297.15.2.186

Zenner, C., Herrnleben-Kurz, S., \& Walach, H. (2014). Mindfulnessbased interventions in schools-a systematic review and metaanalysis. Frontiers in Psychology, 5, 603. https://doi.org/10.3389/ fpsyg.2014.00603

Zvolensky, M.J., Farris, S.G., Schmidt, N.B., \& Smits, J.A.J. (2014). The role of smoking inflexibility/avoidance in the relation between anxiety sensitivity and tobacco use and beliefs among treatment-seeking smokers. Experimental and Clinical Psychopharmacology, 22(3), 229-237. https://doi.org/10.1037/a0035306 